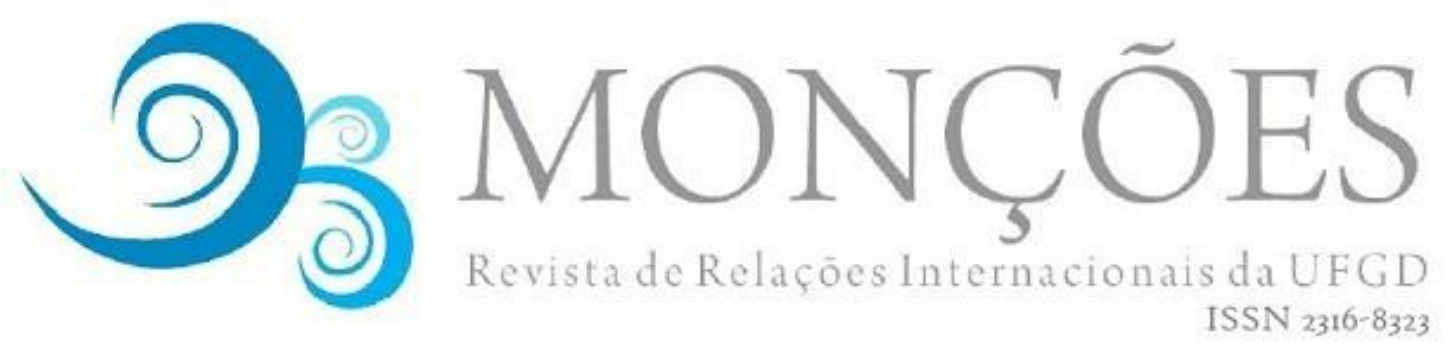

\title{
REGÍMENES INTERNACIONALES \\ $Y$ \\ ORGANIZACIONES INTERGUBERNAMENTALES: PREFERENCIAS Y VALORACIONES POLÍTICAS DESDE URUGUAY
}

CAMILO LÓPEZ BURIAN

Profesor Asistente en el Instituto de Ciencia Política de la Facultad de Ciencias Sociales de la Universidad de la República (UdelaR), Uruguay. Doctor en Ciencia Política (UdelaR). Investigador Activo Nivel I del Sistema Nacional de Investigadores de la Agencia Nacional de Investigación e Innovación (ANII).

FEDERICO IRAZABAL

Profesor Adjunto en la Facultad de Ciencias Humanas de la Universidad Católica del Uruguay, Sociólogo. Actualmente cursando la Maestría en Ciencia Política en el Instituto de Ciencia Política de la Facultad de Ciencias Sociales de la Universidad de la República

(UdelaR), Uruguay.

Resumen: Este trabajo presenta una mirada empírica a las preferencias y valoraciones que los actores políticos uruguayos tienen sobre diferentes regímenes internacionales. A la vez que se presentan, subsidiariamente, algunos datos de opinión pública con el fin de realizar reflexiones preliminares sobre algunas opiniones presentes en los ciudadanos. En el caso de las preferencias de los parlamentarios la pertenencia partidaria y la dimensión ideológica parecen estructurar los posicionamientos. Mientras que las opiniones de los ciudadanos se presentan mucho más homogéneas, no mostrando las divergencias que se observan en los parlamentarios. A partir de estos análisis se realizan algunas reflexiones sobre las posibles explicaciones de los fenómenos visibilizados y se proponen algunas líneas para investigaciones futuras.

Palabras Claves: Regímenes Internacionales - Partidos Políticos - Ciudadanos

\section{INTERNATIONAL REGIMES AND INTERGOVERNMENTAL ORGANIZATIONS: PREFERENCES AND POLITICAL ASSESSMENTS FROM URUGUAY}

\begin{abstract}
This paper presents an empirical approach on the preferences and political assessments that Uruguayan political actors have regarding different international regimes. Some public opinion data is also presented to make preliminary reflections on some opinions expressed by citizens. Parliament members' preferences seem to be structured by their partisanship and an ideological dimension. On the other hand, citizens' opinions are more homogeneous, not showing important divergences as in the case of parliament members. Based on these analyzes, we reflect on the possible explanations of these phenomena and propose some lines for future research.
\end{abstract}

Keywords: International Regimes - Intergovernmental Organizations - Political Parties - Citizens 


\section{A modo de introducción: las preguntas iniciales y los marcos de referencia}

¿Cómo valoran los principales actores de la política exterior uruguaya a los regímenes internacionales? ¿Hay diferencias en las preferencias de los actores? De encontrarlas, ¿qué factores explicarían estas divergencias? ¿Las preferencias de estos actores reflejan las de la ciudadanía? Para responder estas preguntas, este trabajo realiza un ejercicio empírico sobre el caso uruguayo.

En Uruguay el sistema político tiene a los partidos, y sus fracciones sectores internos de alta visibilidad con liderazgos fuertes-, como actores centrales aunque no excluyentes (CAETANO et al, 1987). Específicamente hay trabajos que señalan esta centralidad en la arena de la política exterior (LUJÁN, 2010 y CAETANO et al, 2015) en el marco de un régimen de gobierno presidencialista. El sistema de partidos uruguayo es altamente institucionalizado, con una relativa estabilidad de su competencia electoral (BUQUET y PIÑEIRO, 2014) y en el plano de la política exterior tiene en la ideología ${ }^{1}$ y la disciplina partidaria ${ }^{2}$ dos de sus claves explicativas (LOPEZ BURIAN, 2015).

La mirada que se propone aquí sobre la política exterior uruguaya pone el foco sobre una serie de asuntos que generan tensiones políticas. Un aspecto clave refiere a la apuesta a los procesos e institucionalidad regional, la cual se contrapone -en el debate político de los actores-, muchas veces, con la apuesta a la apertura al mundo y la inserción en el espacio global. Este debate se relaciona con la pertenencia a diferentes regímenes internacionales. Como se verá en la sección de análisis, los actores políticos tienen preferencias divergentes, particularmente sobre el lugar que ocupa la dimensión regional en la estrategia de la política exterior y por consiguiente el grado de involucramiento con la institucionalidad regional.

Cuando se abordan estos asuntos, se están discutiendo, por una parte, elementos vinculados al desarrollo y, por otra, a la soberanía. Luis Felipe Lampreia ${ }^{3}$ (1998) señalaba que la integración regional conlleva a diferentes formas de

\footnotetext{
${ }^{1}$ Destacando el potencial explicativo de esta variable pueden consultarse los trabajos de THERIÉN y NOEL, 2000; MILNER y JUDKINS 2004; MARKS, WILSON y RAY, 2006.

${ }^{2}$ Enfatizando el poder explicativo de este factor puede consultarse el trabajo de MALLOY, 2003.

${ }^{3}$ Luiz Felipe Lampreia fue Canciller de Brasil durante el gobierno de Fernando Henrique Cardoso. Estuvo al frente de Itamaraty desde 1995 hasta 2001, liderando el proceso de redefinición conceptual de la autonomía de Brasil en política exterior, pasando de una noción de aislamiento y autosuficiencia a una visión de autonomía mediante la integración, entendiendo por esta última, el apoyo a los regímenes internacionales (SARAIVA y TEDESCO, 2003, p.498).
} 
soberanía compartida que implican el apoyo a regímenes internacionales ${ }^{4}$. Stephen Krasner define a éstos regímenes como principios, normas, reglas y procedimientos de decisión en torno a los cuales convergen las expectativas de un determinado campo de actividad (1982). Por su parte Robert Keohane y Joseph Nye conceptualizan a los regímenes internacionales como redes de reglas, normas y procedimientos que configuran el comportamiento y controlan sus efectos en un campo de actividad (1988). Maria Izabel Mallmann, desde esta perspectiva y siguiendo el derrotero conceptual de Ernst Haas (1961) señala que la integración regional "“[...] conduz, em última instância, à sujeição dos estados a instâncias institucionais mais amplas, às quais diferentes agentes de diversas nacionalidades transferem, mediante incentivos, suas lealdades [...]". (MALLMANN, 2010, p.13).

Si bien el centro de este trabajo está en los regímenes internacionales, se presentan y analizan preferencias y valoraciones sobre elementos diferentes pero que poseen relaciones entre sí, o que se relacionan en los mapas cognitivos de los actores, a veces hasta solapadamente. Por ejemplo, en el caso analizado, el espacio geográfico regional priorizado por los actores tiene un correlato con la institucionalidad desarrollada en el mismo. En consonancia con la tradición liberal ${ }^{5}$ en relaciones internacionales, se conciben aquí a las organizaciones intergubernamentales (OIG) como foros para el accionar de los Estados y a la vez que se constituyen con éstos en promotores de la creación y mantenimiento de principios y reglas que en conjunto se conocen como regímenes internacionales. A la vez que las OIG incorporan en sus estatutos los procesos decisorios, reglas y normas de los diferentes regímenes. Los principios de un régimen internacional pueden encontrarse articulados en diferentes tratados internacionales que los institucionalizan en normas y reglas específicas. Las OIG brindan a sus miembros un foro para articular esfuerzos y favorecen a la interacción internacional de los agentes, a la vez que limitan o afectan sus agendas tanto internacionales como locales. (MINGST 2006, p.277-282).

Atendiendo a lo antes expuesto, la apuesta por participar de diferentes OIG y

\footnotetext{
${ }^{4}$ La primera definición conceptual de régimen internacional fue realizada por John Ruggie (1975, p.570) quien lo concebía como un conjunto de mutuas expectativas, normas y regulaciones, planes, energías organizativas y compromisos financieros aceptado por un grupo de Estados.

${ }^{5}$ Un análisis de la diversidad de la escuela liberal y sus trayectorias neoliberal e institucionalista ver Grasa (2015).
} 
regímenes internacionales es un asunto de debate en el caso uruguayo. Su carácter regional o global, los temas abarcados en los mismos y cómo afectan al desarrollo y a la soberanía se constituyen en puntos sensibles del debate político. Esbozar una respuesta sobre los factores que causan esta polarización es uno de los objetivos de este trabajo.

Un análisis, anteriormente realizado ${ }^{6}$, sobre el apoyo que los actores políticos uruguayos a coordinar la política de Defensa Nacional en el marco del Consejo Sudamericano de Defensa de UNASUR muestra que la ideología es un factor asociado positivamente al apoyo a esta iniciativa. Es de esperarse que la ideología sea un factor relevante a la hora de estructurar las preferencias de los actores políticos en relación a los regímenes internacionales.

Otro aspecto que resulta de interés en este trabajo se refiere a la convergencia que las preferencias de los actores políticos tienen con las de la ciudadanía. Al trabajar con preferencias de parlamentarios, vale la pena referir a la literatura del análisis de política exterior que señala un desinterés de estos actores sobre esta materia, basándose en el supuesto de una percepción de bajo retorno electoral (ROSENAU, 1967; HOLSTI, 1992). Por otra parte, al ser una política pública "alejada" de los electores, los mismos tendrían pocos incentivos para buscar generar efectos sobre la conducta de los parlamentarios en esta arena (PATERSON, 1979). Siguiendo este enfoque, comparados con los asuntos domésticos, la política exterior sería menos relevante para los electores, ya que tendrían menor conocimiento relativo sobre los asuntos internacionales y por la volatilidad de la opinión pública (LIPSET, 1966; RISSE-KAPEN, 1991; PAGE y BOUTON, 2006). Otro grupo de académicos (WITKOPF, 1990), por el contrario, conciben a la opinión pública como estable, estructurada y racional, considerándola un factor interviniente en el proceso decisorio de la política exterior (HARTLEY y RUSSET, 1992; SOBEL, 2001). Dados estos planteos, vale la pena preguntarse, para el caso uruguayo, cuál es el grado de convergencia que las preferencias de los parlamentarios tienen con las de la ciudadanía.

Presentado en este apartado los asuntos sobre los que se indaga en este

${ }^{6}$ Ver LÓPEZ BURIAN, 2014. 
texto, el siguiente se concentra en presentar los métodos y datos utilizados. Posteriormente la sección analítica se divide en dos partes, siendo central la primera en la que el trabajo aborda en las preferencias y valoraciones de los parlamentarios. Posteriormente y de forma subsidiaria, se exploran datos de opinión pública con el fin de obtener indicios sobre las preferencias de los ciudadanos, con el fin de realizar algunas reflexiones sobre las mismas y avanzar en esbozos comparativos con la opinión de los parlamentarios. Para cerrar el trabajo se subrayan algunos elementos que pueden constituir en elementos para una agenda de investigación empírica más ambiciosa.

\section{Métodos y datos}

El trabajo propone un análisis que presenta datos sobre las preferencias de los parlamentarios uruguayos de la pasada legislatura (2010-2015) por un lado, y por el otro las preferencias de ciudadanos de todo el país recogidas a partir del Estudio Mundial de Valores.

En el caso de los parlamentarios, los datos cuantitativos son producto de la aplicación de una encuesta que logró cubrir el 96\% del universo. Se recogieron, procesaron y analizaron las respuestas de 125 de los 130 parlamentarios (99 diputados, 30 senadores y el Vicepresidente de la República quien preside el Senado y la Asamblea General).

Dado el carácter partidocrático del sistema político uruguayo (CAETANO et al, 1987), la política exterior uruguaya tiene a los partidos como actores centrales. Una forma de conocer las preferencias partidarias es tomar como unidades de observación a los parlamentarios. En Uruguay, los líderes partidarios, generalmente, detentan cargos legislativos en el Senado, salvo cuando ocupan cargos ejecutivos. De esta forma al tomar a los parlamentarios como unidades de observación pueden construirse posteriormente unidades de análisis que muestran las preferencias agrupadas de, por ejemplo, todos los miembros del cuerpo legislativo uruguayo electos por determinado partido.

En forma complementaria se obtuvo información cualitativa sobre los asuntos aquí analizados. Para ello se realizaron 50 entrevistas en profundidad a 
actores políticos e informantes calificados. Los entrevistados fueron seleccionados mediante una muestra finalística a juicio de experto, teniendo como fin el lograr información clave sobre aspectos puntuales y procesos de interés. Por otra parte, para ilustrar algunos asuntos del argumento que aquí se plantea, se optó por apoyarse en notas de prensa aunque de forma no sistemática.

Los datos referidos a las preferencias de los ciudadanos se tomarán de la base de la Encuesta Mundial de Valores (EMV), un proyecto originado en la Universidad de Michigan, y que se lleva adelante desde 1981, cuando se realizó una primera edición, que abarcó unos cien países.

Su objetivo es medir valores y opiniones de habitantes de distintos países, y observar, en mediciones periódicas, como van cambiando las opiniones y valores en diferentes sociedades. A partir de la aplicación de un formulario que mide más de 200 variables, la EMV arroja información que permite observar el estado de la opinión pública en referencia a asuntos tales como: el lugar que ocupa y la importancia asignada a la religión; el apoyo a valores democráticos y republicanos; el rol de las mujeres; la percepción de las minorías; la inseguridad y el bienestar, entre otros.

La EMV es especialmente útil para conocer los valores de una sociedad, a partir de la comparación con otras sociedades, ya que como señala Alejandro Moreno, "Nuestros valores forman parte de un sistema global de creencias y para entenderlos hay que referirnos a los valores que prevalecen en otras sociedades." (MORENO, 2005, p.31).

Como señalamos anteriormente, la EMV se realiza en forma periódica en intervalos que han variado entre los tres y los cinco años. La primera ronda se efectuó entre 1981 y 1984, mientras que última que se encuentra procesada, la sexta, abarca el período comprendido entre 2010 y 2014. Actualmente está en curso la séptima edición, que tiene fecha de cierre previsto para diciembre de 2019.

Como es habitual al utilizar la técnica de encuesta, se aplica un formulario para relevar la información, el que también ha sufrido variaciones a lo largo de los distintos ciclos de aplicación de la encuesta. A los efectos de favorecer la compatibilidad de los datos obtenidos en la encuesta a legisladores, con los datos de 
opinión pública reflejados en la EMV, hemos optado por trabajar con la quinta edición, efectuada entre 2005 y 2009, pero que recogió los datos de Uruguay en 2006. Esta edición utilizó una muestra representativa a nivel nacional, tomando un total de 1000 casos distribuidos en un $50 \%$ en Montevideo, la capital del país (que concentra aproximadamente la mitad de la población), y el restante $50 \%$ en el interior del país en localidades de más de 5000 habitantes.

Existe un desfase en la fecha de relevamiento de datos de los parlamentarios uruguayos con respecto a los proporcionados por el Estudio Mundial de Valores. Los datos de este último -como se señaló- fueron relevados en 2006, mientras que la encuesta a legisladores se aplicó en 2013. El lector podrá correctamente asumir que podrían haberse utilizado datos de la siguiente ronda del EMV, correspondiente al período 2010-2014. Sin embargo, esa ronda no incluyó preguntas referidas a mecanismos de resolución de conflictos por parte de OI, y por tanto no se vería reflejado el estado de la opinión pública de los uruguayos en comparación con la de los legisladores. El desfasaje en los años de recolección de los datos relativos a las preferencias de legisladores y ciudadanos hace que las reflexiones aquí recogidas al observar la información procesada solamente busquen proponer líneas de trabajo futuro y sirvan como insumos para refinar preguntas y pensar hipótesis, ya que la realización de análisis de otro calibre exceden a las posibilidades que los datos brindan y a los objetivos del presente trabajo.

Como surge a partir de la descripción de las fuentes de datos y el tipo de análisis a realizar, este trabajo es de carácter no sistemático, y por tanto carece de carácter representativo a excepción del caso al que refiere.

\section{Análisis de los datos}

\subsection{Los parlamentarios frente a los regímenes internacionales}

El carácter partidocrático del sistema político uruguayo y, por consiguiente, de la arena de la política exterior permite que, al analizar las preferencias de los parlamentarios, se esté observando el posicionamiento de los partidos políticos. 
Ideológicamente estables, la imagen que arrojan tanto la autoidentificación ideológica como el juicio de todos los parlamentarios o la que tienen sobre su propio partido muestra una gran coherencia. Mientras el Frente Amplio (FA) aparece en la izquierda, el Partido Independiente (PI) ocupa el centro del espectro, mientras que el Partido Nacional (PN) y el Partido Colorado (PC) aparecen en la centroderecha. Estos dos últimos, además, muestran un alto grado de superposición $(70,7 \%)$, mientras el PI aparece más convergente ideológicamente con el PN y el PC (55\%) que con el FA (24,2\%). A nivel intrapartidario, el PI no muestra fracciones ${ }^{7}$, mientras que el PC y el PN presentan una mayor homogeneidad ideológica entre sus fracciones que la imagen que proyecta el FA de su dimensión intrapartidaria ${ }^{8}$.

Tabela 1: Partidos uruguayos ubicados en el eje izquierda-derecha (2010 2015).

\begin{tabular}{|cccccccccc|}
\hline & \multicolumn{2}{c}{ Todos } & \multicolumn{3}{c}{ Cada partido } & \multicolumn{2}{c|}{ Autoidentificación } \\
\hline & Media & $\begin{array}{c}\text { Desviación } \\
\mathbf{n} \\
\text { estándar }\end{array}$ & $\mathbf{( N )}$ & Media & $\begin{array}{c}\text { Desviación } \\
\text { estándar }\end{array}$ & $\mathbf{( N )}$ & Media & $\begin{array}{c}\text { Desviació } \\
\mathbf{n} \\
\text { estándar }\end{array}$ & (N) \\
\hline $\begin{array}{c}\text { Frente } \\
\text { Amplio } \\
\text { (FA) }\end{array}$ & 3,83 & 1,25 & 123 & 3,67 & 0,97 & 66 & 2,74 & 1,12 & 66 \\
\hline $\begin{array}{c}\text { Partido } \\
\text { Colorad } \\
\text { o (PC) }\end{array}$ & 7,55 & 1,57 & 124 & 5,88 & 1,07 & 19 & 5 & 0,83 & 20 \\
\hline
\end{tabular}

\footnotetext{
${ }^{7}$ Definidas como listas al Senado. Uruguay tiene un sistema de listas cerradas y bloqueadas. EI Senado es una circunscripción única nacional.

${ }^{8}$ En este trabajo se trabaja con agrupamientos de fracciones que se conceptualizan como alas ideológicas de partido. La totalidad de los parlamentarios, los partidos, sus fracciones y las alas de partido son las unidades de análisis que se toman en cuenta. Las alas de partido se definieron siguiendo el criterio propuesto por Luis Eduardo González (1993, p.115). La media de la autoidentificación de los miembros de cada partido se tomó como división del partido en dos alas, un ala derecha y un ala izquierda. Para definir la ubicación de cada fracción, se tomó la media de la autoidentificación de sus miembros, mientras que su posicionamiento en relación con la media del partido las hace formar parte de una $u$ otra ala del mismo. Esta denominación no supone por ejemplo que el ala derecha del FA se encuentre a la derecha del continuo en general, sino que refiere a la posición relativa dentro del partido. El FA muestra la mayor distancia entre las medias de sus alas $(0,85)$ y sus parlamentarios medianos llegan a tener una distancia de un punto. Por el contrario, el PC y el PN muestran alas superpuestas en más de un $80 \%$.
} 


\begin{tabular}{|cccccccccc|}
\hline $\begin{array}{c}\text { Partido } \\
\text { Nacional } \\
\text { (PN) }\end{array}$ & 7,11 & 1,31 & 123 & 5,64 & 0,71 & 35 & 5,44 & 1,02 & 35 \\
\hline $\begin{array}{c}\text { Partido } \\
\text { Indepen } \\
\text { diente } \\
\text { (PI) }\end{array}$ & 5,56 & 1,1 & 122 & 4 & 0,7 & 2 & 4,5 & 0,71 & 2 \\
\hline
\end{tabular}

Fonte: Elaboração dos autores a partir de pesquisa realizada com parlamentares uruguaios.

Como se verá más adelante, la valoración que los mismos hacen de diferentes regímenes internacionales muestra relación con cómo se distribuyen sus preferencias en relación a apostar a los espacios regionales y globales en diferente proporción. Consultados los parlamentarios sobre cuál es el foco territorial que debería priorizar la política exterior uruguaya, poco menos de la mitad de los parlamentarios apuesta a la apertura al mundo, poco menos de un tercio a la región y casi un cuarto se inclina por el equilibrio entre la región y el mundo.

La lectura de estos datos, y del resto que se presentan en esta sección, merecen una puntualización sobre el contexto nacional e internacional que enmarca las preferencias expresadas por los legisladores. Al momento de la recolección de los datos el FA transitaba su segundo período de gobierno consecutivo, siendo en ese momento José Mujica el presidente de la República, quien contaba con mayoría parlamentaria en ambas cámaras. La oposición, dado el contexto parlamentario señalado, tenía incentivos para distanciarse del gobierno y visibilizar sus discrepancias en temas sustantivos de políticas públicas y en la forma de tramitación política de las mismas.

La política exterior se constituyó en un asunto de debate interpartidario. En este período, el entonces ministro de Relaciones Exteriores, Luis Almagro, fue doce veces al Parlamento a brindar explicaciones solicitadas por legisladores de la oposición, siendo el ministro que más veces fue convocado de todo el período 20102015 y el ministro de Relaciones Exteriores que más veces compareció en el Parlamento luego del retorno a la democracia en 1985. (LÓPEZ BURIAN, 2015, p.114). La política exterior en el período profundizó la apuesta por la integración regional, las relaciones Sur-Sur y por la alianza con Brasil en particular: 
Desde el inicio de su gobierno, el presidente José Mujica señaló que el país debía ir "en el estribo de Brasil" [...]. A esas palabras que expresaban a las claras la priorización por la región, se le sumó un discurso orientado a destacar la relevancia estratégica de que el país se involucrara en una promoción de las relaciones Sur-Sur, no solamente basadas en aspectos económico-comerciales sino también políticos. Desde la oposición se confrontó esta orientación reivindicando un accionar de la política exterior más pragmático y focalizado en los aspectos económico-comerciales. De ese modo se generó, desde la oposición, un discurso que tendía a enfrentar la prioridad de los objetivos comerciales y de una estrategia más pragmática y menos ideológica, frente a una estrategia gubernamental que se describía como basada en las afinidades ideológicas y en un excesivo énfasis en los asuntos políticos. (CAETANO et al, 2015, p.290).

La evaluación del contexto internacional que los actores políticos uruguayos realizaban en ese momento daba cuenta de los efectos de la crisis internacional a nivel global y regional. El ámbito regional era percibido como una arena de gran importancia por todos los actores, aunque para unos era un espacio que "encerraba" a Uruguay y para otros la forma de construcción de un proyecto de desarrollo en clave regional. (LÓPEZ BURIAN, 2015, p.268-273). Brasil ya mostraba una priorización menor de su agenda internacional, en términos comparados con los gobiernos de Luiz Inácio Lula da Silva (2003-2010), pero esto no era percibido desde Uruguay como una disminución pronunciada de su presencia e importancia regional y global. A pesar de esta mayor exposición de la temática internacional en la agenda política, no se vio un impacto significativo de la más asidua comparecencia del canciller Almagro al Parlamento a nivel de la opinión pública, probablemente por la distancia ya señalada de los ciudadanos con los temas de relaciones internacionales. A grandes rasgos, si bien hubo un cambio en la fracción gobernante, y un énfasis mayor en la mirada hacia Brasil, probablemente los matices en la orientación de la política exterior entre ambos gobiernos del FA no fueron fácilmente percibidos por los ciudadanos.

Tabela 2: Foco territorial prioritario de la política exterior, por partido.

\begin{tabular}{|cccc|}
\hline & Región & Mundo & Ambas \\
\hline Partido & $\%$ & $\%$ & $\%$ \\
\hline FA & 47,0 & 24,2 & 28,8 \\
\hline Ala izquierda FA & 55,6 & 22,2 & 22,2 \\
\hline Ala derecha FA & 36,7 & 26,7 & 36,7 \\
\hline PN & 13,9 & 63,9 & 22,2 \\
\hline Ala izquierda PN & 18,8 & 56,3 & 25,5 \\
\hline
\end{tabular}




\begin{tabular}{|cccc|}
\hline Ala derecha PN & 10,0 & 70,0 & 20,0 \\
\hline PC & 9,5 & 76,2 & 14,3 \\
\hline Ala izquierda PC & - & 100,0 & - \\
\hline Ala derecha PC & 12,5 & 68,8 & 18,8 \\
\hline PI & - & 50,0 & 50,0 \\
\hline
\end{tabular}

Fonte: Elaboração dos autores a partir de pesquisa realizada com parlamentares uruguaios.

En este contexto, a pesar de algunas percepciones compartidas, las preferencias mostraban divergencias interpartidarias y también dentro del partido de gobierno. Segmentando los datos por partido, poco menos de la mitad de los parlamentarios del FA, ubicados a la izquierda del espectro ideológico, consideran que la prioridad debe ser la región (ver la tabla 2). La segunda preferencia dentro del FA es el equilibrio entre la región y el mundo, casi un tercio, mientras que poco más de un cuarto señala que la prioridad debe ser el mundo. En el caso del PN y el FA si hay una preferencia que unitariamente logra superar la mitad de los parlamentarios, mostrando más homogeneidad que el FA, tal vez relacionándose con las características del posicionamiento ideológico antes señalado.

PC y PN, mayoritariamente se decantan por la apertura al mundo. En el partido ubicado más a la derecha, el PC, la apertura al mundo como preferencia alcanza a tres cuartos de los parlamentarios, mientras que en el PN abarca casi dos tercios. En términos generales ambos partidos tienen una mirada crítica sobre el proceso de integración regional del Mercosur. En este sentido, en 2012, afirmaba el ex Presidente nacionalista Luis Alberto Lacalle:

Yo no reconozco este Mercosur como mi hijo. Con los otros tres padres que fundamos dijimos que el objetivo era el comercio libre, inversiones, más trabajo, pero no para un club político y menos para un club político de izquierda. Mercosur se volvió una especie de liga de políticos de izquierda (Portal 180 01/07/2012).

Esta visión es convergente con la postura mayoritaria dentro del PC. El ex Presidente Jorge Batlle en relación a la priorización de la apertura al mundo señalaba en 2014 que:

[...] que Uruguay, dentro del Mercosur, tiene poco margen de maniobra. 'Hoy para participar hay que formar parte de una región más grande, si no, no estás en el juego, afirmó. Batlle recordó que quien 'inventó' el Mercosur político fue 'nuestro amigo' Fernando Henrique Cardoso, expresidente brasileño. Transformo el bloque en un 'proyecto político, no comercial, y eso 
quitó margen de maniobra' a Uruguay. El país, para ganar amplitud, debe ver cómo se suma al mundo, continuó el exmandatario. (El Observador 13/01 2014).

En consonancia, Pablo Mieres, líder del PI, señalaba en febrero de 2013 la importancia de que Uruguay se integrase a la Alianza del Pacífico:

\begin{abstract}
La crisis del Mercosur, en todas sus dimensiones, es cada vez más notoria. Después de haber sido la mayor apuesta latinoamericana de integración en los años noventa, desde hace más de una década se ha ido desgastando hasta llegar a su realidad actual, en la que ni siquiera ha mantenido el respeto por sus propias normas de funcionamiento ni por los principios del derecho internacional. [...] En las actuales condiciones poco o nada se puede esperar de ese espacio de integración regional. Esto no significa que pregonemos su abandono o retiro, pero sí que asumamos la evidencia de los hechos y que apostemos a desarrollar, con vigor y energía, una estrategia alternativa. (Primera Hora 06/02/2013).
\end{abstract}

Segmentados los datos por ala de partido, tanto el PC como el PN muestran preferencias relativamente homogéneas. En el caso del FA, mientras que su ala izquierda muestra que más de la mitad prioriza la región, su ala derecha presenta la misma cantidad de priorizaciones de la región que de equilibrio entre la región y el mundo.

Una cuestión no menor es intentar determinar cuál es la región a la que los parlamentarios hacen referencia al señalar que debe ser priorizada como foco territorial o priorizada en equilibrio con la apertura al mundo. Para ello, en la encuesta realizada se agregó una pregunta abierta en la que se consultaba cuál era la región a la que hacían referencia los parlamentarios al incluirla dentro del foco territorial prioritario de la política exterior.

Tabela 3. Región a la priorizada en política exterior por los parlamentarios, por partido.

\begin{tabular}{|c|c|c|c|c|}
\hline \multicolumn{3}{|c|}{ Partido } & $\%$ & \% válido \\
\hline \multirow[t]{7}{*}{ FA } & \multirow[t]{5}{*}{ Válidos } & Mercosur & 13,6 & 17,6 \\
\hline & & Sudamérica & 22,7 & 29,4 \\
\hline & & Latinoamérica & 37,9 & 49,0 \\
\hline & & Mercosur al mundo & 3,0 & 3,9 \\
\hline & & Total & 77,3 & 100,0 \\
\hline & Perdidos & No corresponde que respondan & 22,7 & \\
\hline & Total & & 100,0 & \\
\hline \multirow[t]{3}{*}{ PN } & \multirow[t]{3}{*}{ Válidos } & Río de la Plata & 5,6 & 15,4 \\
\hline & & Mercosur & 16,7 & 46,2 \\
\hline & & Sudamérica & 2,8 & 7,7 \\
\hline
\end{tabular}




\begin{tabular}{|cllcc|}
\hline & & Hispanoamérica & 2,8 & 7,7 \\
\cline { 3 - 5 } & & Latinoamérica & 2,8 & 7,7 \\
\cline { 3 - 5 } & & Las Américas & 5,6 & 15,4 \\
\cline { 3 - 5 } & & Total & 36,1 & 100,0 \\
\cline { 3 - 5 } & Perdidos & No corresponde que respondan & 63,9 & \\
\cline { 3 - 5 } & Total & & 100,0 & 40,0 \\
\hline PC & Válidos & Mercosur & 9,5 & 20,0 \\
\cline { 3 - 5 } & & Latinoamérica & 4,8 & 40,0 \\
\cline { 3 - 5 } & & Las Américas & 9,5 & \\
\cline { 3 - 5 } & & Total & 23,8 & 100,0 \\
\cline { 2 - 5 } & Perdidos & No corresponde que respondan & 76,2 & \\
\cline { 2 - 5 } & Total & & 100,0 & \\
\hline PI & Válidos & Cono sur & 50,0 & \\
\cline { 2 - 5 } & Perdidos & No corresponde que respondan & 50,0 & \\
\cline { 2 - 5 } & Total & & 100,0 & \\
\hline
\end{tabular}

Fonte: Elaboração dos autores a partir de pesquisa realizada com parlamentares uruguaios.

Como puede verse en la tabla 3, los frenteamplistas se refieren mayoritariamente a Latinoamérica. Cinco de cada diez que mencionaron a la región dentro de sus preferencias hacen referencia a este espacio. Tres de cada diez hacen referencia a Sudamérica y dos al Mercosur. En el caso del PC y PN, la primera preferencia cuando se hace referencia a la región es el Mercosur. En el caso del PC en la misma proporción que las Américas, entendido este espacio como incluyente de EEUU y Canadá. Esto muestra una tendencia aperturista y se relaciona con su tradición panamericanista de este partido. En el caso del PN las Américas comparten el segundo lugar en las preferencias junto al espacio del Río de la Plata, reivindicado como el primer espacio natural de la política exterior, asociado a lo hispanocriollo y a la tradición de este partido política exterior.

Una forma de continuar profundizando la comprensión sobre cuál es el foco territorial referido y su relación con los regímenes internacionales fue consultar a los parlamentarios sobre qué institución se aproximaba a la idea de región que cada uno había manifestado. Esto muestra algunos aspectos que merecen reflexiones enriquecidas con algunos argumentos surgidos del análisis de las entrevistas en profundidad.

Tabela 4: Institución aproximada a la idea de región priorizada en política exterior por los parlamentarios por partido. 


\begin{tabular}{|c|c|c|c|c|}
\hline \multirow{2}{*}{$\begin{array}{l}\text { Partido } \\
\text { FA }\end{array}$} & & & $\%$ & \% válido \\
\hline & \multirow[t]{4}{*}{ Válidos } & Mercosur & 19,7 & 25,5 \\
\hline & & UNASUR & 43,9 & 56,9 \\
\hline & & CELAC & 13,6 & 17,6 \\
\hline & & Total & 77,3 & 100,0 \\
\hline & Perdidos & $\begin{array}{l}\text { No corresponde que } \\
\text { respondan }\end{array}$ & 22,7 & \\
\hline & Total & & 100,0 & \\
\hline \multirow[t]{6}{*}{ PN } & \multirow[t]{4}{*}{ Válidos } & Mercosur & 22,2 & 61,5 \\
\hline & & UNASUR & 2,8 & 7,7 \\
\hline & & OEA & 11,1 & 30,8 \\
\hline & & Total & 36,1 & 100,0 \\
\hline & Perdidos & $\begin{array}{l}\text { No corresponde que } \\
\text { respondan }\end{array}$ & 63,9 & \\
\hline & Total & & 100,0 & \\
\hline \multirow[t]{7}{*}{ PC } & \multirow[t]{5}{*}{ Válidos } & Mercosur & 9,5 & 40,0 \\
\hline & & UNASUR & 4,8 & 20,0 \\
\hline & & CELAC & 4,8 & 20,0 \\
\hline & & OEA & 4,8 & 20,0 \\
\hline & & Total & 23,8 & 100,0 \\
\hline & Perdidos & $\begin{array}{l}\text { No corresponde que } \\
\text { respondan }\end{array}$ & 76,2 & \\
\hline & Total & & 100,0 & \\
\hline \multirow[t]{3}{*}{ PI } & Válidos & Mercosur & 50,0 & 100,0 \\
\hline & Perdidos & $\begin{array}{l}\text { No corresponde que } \\
\text { respondan }\end{array}$ & 50,0 & \\
\hline & Total & & 100,0 & \\
\hline
\end{tabular}

Fonte: Elaboração dos autores a partir de pesquisa realizada com parlamentares uruguaios.

Si se comparan las preferencias por partido resumidas en las tablas 3 y 4 se notará que en el caso del FA donde la región privilegiada en primer lugar era América Latina, a la hora de pensar en una institución es la UNASUR quien se posiciona en primer lugar. A su vez la segunda preferencia que aparece en el caso del FA en la tabla 3 es Sudamérica, pero en la tabla 4 este lugar lo ocupa el Mercosur, mientras que la CELAC, la institución que más se asemeja a la idea de Latinoamérica cae al tercer lugar de las preferencias. Primero debe señalarse que la densidad institucional de la CELAC, la UNASUR y el Mercosur son diferentes. La primera es quien tiene un menor grado de institucionalización, lo que de alguna forma debe impactar en las respuestas de los parlamentarios. Luego debe decirse que UNASUR es visibilizado como un proyecto integrador que va más allá de lo 
comercial, en el que se aparecen elementos, políticos y de infraestructura vinculadas a lo productivo y los recursos naturales regionales, que lo hacen estratégico en la mirada de varios de los entrevistados de izquierda. Luego, debe señalarse un proceso que parece darse en el análisis de varios entrevistados. Algunos son "sudamericanistas por retracción" de su identidad latinoamericana o su concepción regional latinoamericanista, al ver a México, América Central y al Caribe como el "patio trasero" ya "perdido" por la hegemonía que ejerce EEUU. En este caso la solidaridad con Cuba es un tema irresuelto en estas definiciones. Otros, originariamente mercosurianos, sea por los problemas que el proceso ha registrado en algunas de sus dimensiones de integración o por una valorización mayor de UNASUR, se han vuelto "sudamericanistas por expansión".

Tabela 5: Institución aproximada a la idea de región priorizada en política exterior por los parlamentarios por ala de partido.

\begin{tabular}{|c|c|c|c|c|}
\hline Ala & & & $\%$ & $\begin{array}{c}\% \\
\text { válido }\end{array}$ \\
\hline \multirow{6}{*}{$\begin{array}{l}\text { Ala } \\
\text { izquierda } \\
\text { FA }\end{array}$} & \multirow[t]{4}{*}{ Válidos } & Mercosur & 8,3 & 10,7 \\
\hline & & UNASUR & 50,0 & 64,3 \\
\hline & & CELAC & 19,4 & 25,0 \\
\hline & & Total & 77,8 & 100,0 \\
\hline & Perdidos & No corresponde que respondan & 22,2 & \\
\hline & Total & & 100,0 & \\
\hline \multirow{6}{*}{$\begin{array}{l}\text { Ala } \\
\text { derecha } \\
\text { FA }\end{array}$} & \multirow[t]{4}{*}{ Válidos } & Mercosur & 33,3 & 43,5 \\
\hline & & UNASUR & 36,7 & 47,8 \\
\hline & & CELAC & 6,7 & 8,7 \\
\hline & & Total & 76,7 & 100,0 \\
\hline & Perdidos & No corresponde que respondan & 23,3 & \\
\hline & Total & & 100,0 & \\
\hline
\end{tabular}

Fonte: Elaboração dos autores a partir de pesquisa realizada com parlamentares uruguaios.

Desde el ala izquierda del FA, algunos parlamentarios identifican a los proyectos regionales con la idea de "Patria Grande". En este sentido un senador señaló durante su entrevista que: "La región es la Patria Grande. México en vez de estar en el NAFTA debería estar con nosotros. [...] pero la que ha funcionado más cerca de la idea de región es la UNASUR." La valoración de este espacio realizada por este senador se reafirma en la no participación estadounidense en este espacio, al igual que en el de la CELAC, al señalar: "Con la UNASUR los latinoamericanos 
nos pusimos los pantalones largos. No tenemos ni un gallego [español] ni un norteamericano [estadounidense] en los organismos. No somos iberoamericanos y a las américas sacale el plural. Con UNASUR y CELAC, que es más nuevo, pero es un camino".

Otro senador del ala izquierda del FA señaló sus preferencias por el ALBA, al decir que: "Lo más avanzado que vemos nosotros como procesos regionales es el ALBA, es un modelo, [...] también son importantes la UNASUR y la CELAC." Otro integrante de esta ala del FA resaltó que existen miradas divergentes sobre el proceso del ALBA dentro de su partido, ya que: "En el Frente hay gente que [...] no entiende el fenómeno Chávez. Se ponen tibios ante la ofensiva de la derecha internacional, de los medios de comunicación, demonizando a Chávez." Como puede apreciarse, el corte entre "familias" de las izquierdas (nacional populares o socialdemócratas) también parece pesar en este tema.

Otros parlamentarios frenteamplistas se posicionan, como se señaló anteriormente, como sudamericanistas por expansión del Mercosur, o por retracción del latinoamericanismo. Mientras un senador señalaba que: "Ir de Mercosur a UNASUR es un retroceso, ir de UNASUR a Mercosur es un avance por el contenido de la definición de ambos procesos", otro senador manifestaba que: "Hay que apostar muy fuertemente a un mundo multipolar. Para eso nos sirve, hoy, apostar a un sudamericanismo, porque América Latina está cortada. [...] México está muy absorbido por Estados Unidos". De esta manera, este último senador concluía diciendo: "La UNASUR es lo posible hoy. Un latinoamericanismo ambicioso no es posible. Si hay un latinoamericanismo cultural, histórico. En lo operativo la clave es Sudamérica".

En el caso del PN, del PC y del PI, cuando se hacer referencia a la región, la opción mayoritaria es la misma: el Mercosur. En el PC no se mantiene la tendencia panamericanista identificada al hablar de regiones, no visibilizándose a la OEA como una clara segunda opción. En el caso del PN, ambas alas colocan a la OEA como la institución que se aproxima más a la segunda preferencia más referida. En este sentido, un senador del ala derecha del PN señala sobre la construcción de espacios regionales que excluyen a EEUU y al resto de miembros del NAFTA:

Yo fortalecería la OEA grandemente porque allí están sentados EEUU, 
Canadá y México. $Y$ todo lo que han inventado estos izquierdistas [UNASUR y CELAC] es porque le tienen miedo a encarar a EEUU, porque es más fácil hablar mal de EEUU en la esquina que ir a enfrentarlo en el boliche [...], si le quieren decir cosas que se las digan en la cara.

Otra aproximación posible sobre el foco territorial prioritario es verlo a través de los regímenes internacionales en tanto entramados institucionales. Para ello se consultó a los parlamentarios sobre cuáles serían las instituciones que se debería apostar a fortalecer a través de la política exterior del país (ver tabla 6). Tomándolos como un único grupo, puede verse como el Mercosur como espacio regional y la ONU como espacio multilateral global, en ese orden, aparecen como los regímenes internacionales a fortalecer.

Tabla 6. Instituciones que deberían fortalecerse a través de la política exterior uruguaya. Frecuencias de respuesta según momento de mención.

\begin{tabular}{|c|c|c|c|c|c|c|c|c|c|c|c|c|c|c|c|c|c|c|c|c|}
\hline \multirow[b]{2}{*}{ Institución } & \multicolumn{4}{|c|}{$\begin{array}{c}\text { Todos los } \\
\text { parlamentarios }\end{array}$} & \multicolumn{4}{|c|}{ FA } & \multicolumn{4}{|c|}{ PN } & \multicolumn{4}{|c|}{ PC } & \multicolumn{4}{|c|}{ PI } \\
\hline & 1 & 2 & 3 & $\boldsymbol{\Sigma}$ & 1 & 2 & 3 & $\boldsymbol{\Sigma}$ & 1 & 2 & 3 & $\boldsymbol{\Sigma}$ & 1 & 2 & 3 & $\boldsymbol{\Sigma}$ & 1 & 2 & 3 & $\boldsymbol{\Sigma}$ \\
\hline ONU & 40 & 8 & 21 & 69 & 9 & 3 & 15 & 27 & 17 & 2 & 6 & 25 & 12 & 3 & 0 & 15 & 2 & 0 & 0 & 2 \\
\hline OEA & 5 & 34 & 10 & 49 & 0 & 3 & 2 & 5 & 2 & 17 & 6 & 25 & 3 & 12 & 2 & 17 & 0 & 2 & 0 & 2 \\
\hline CELAC & 8 & 8 & 20 & 36 & 6 & 7 & 17 & 30 & 1 & 1 & 2 & 4 & 1 & 0 & 1 & 2 & 0 & 0 & 0 & 0 \\
\hline UNASUR & 25 & 34 & 5 & 60 & 21 & 33 & 3 & 57 & 4 & 1 & 0 & 5 & 0 & 0 & 2 & 2 & 0 & 0 & 0 & 0 \\
\hline Mercosur & 44 & 21 & 29 & 94 & 30 & 12 & 14 & 56 & 10 & 7 & 6 & 23 & 4 & 2 & 7 & 13 & 0 & 0 & 2 & 2 \\
\hline NS/NC & 3 & 20 & 40 & - & 0 & 8 & 15 & - & 0 & 8 & 16 & - & 1 & 4 & 9 & - & 0 & 0 & 0 & - \\
\hline
\end{tabular}

Fonte: Elaboração dos autores a partir de pesquisa realizada com parlamentares uruguaios.

Si se observa la columna de la segunda mención de todos los parlamentarios puede notarse como se prefigura una bifurcación en las preferencias. Se visibiliza una divergencia entre un grupo que prefiere la OEA y otro que prefiere la UNASUR. Ambos regímenes son visualizados como contrapuestos básicamente por su componente centralmente político. El primero es un espacio donde EEUU despliega su capacidad de influencia, y donde Brasil se encuentra con su principal competidor, en el ámbito Latinoamericano, México. UNASUR, como columna vertebral del proyecto continental brasileño, particularmente luego del "giro a la izquierda" de la región es valorado negativamente por los partidos de derecha y centro derecha, tanto por la confluencia de gobiernos de izquierda o progresistas en torno al proceso, como por el vector político que estructura a este proceso. 
Un senador de la oposición visualizó al espacio de la Alianza del Pacífico como una dimensión donde "pendular" entre México y Brasil como clave táctica de la política exterior a partir de una reconfiguración del espacio regional, donde Argentina ha perdido peso en los últimos años:

Uruguay construyó su política exterior pendulando entre Argentina y Brasil, porque eran países similares en su peso. Argentina se desplomó y Brasil es potencia. El riesgo de Uruguay es quedar adosado a Brasil. Por eso la Alianza del Pacífico es una oportunidad para vincularse con el nuevo eje mundial y de tener otro polo para pendular, México y sus aliados. [...] Por eso la UNASUR es un invento brasileño contra México. A Brasil hay que aprovecharlo y tener buenas relaciones [...] pero no terminar en una situación de total dependencia a la que estamos encaminados. [...] Brasil es una ventana al mundo y México puede ser otra.

Si se analizan las respuesta, pero ahora segmentándolas por partido, puede verse como en el caso del PC, en términos acumulados, la OEA es el espacio priorizado, lo que es convergente con su tradición panamericanista. A la vez que la ONU aparece como el foro multilateral global, que recibe la mayor cantidad de preferencias en la primera mención. Mientras que el Mercosur aparece en tercer lugar, teniendo la mayoría de las menciones acumuladas en la tercera oportunidad. En el caso del PN, en términos acumulados la ONU y la OEA aparecen como los espacios privilegiados y el Mercosur aparece en tercer lugar, pero tiene el segundo lugar de las preferencias en la primera y en la segunda mención, lo que muestra que una parte de los parlamentarios le visualizan como un espacio relevante. El PI por su parte prioriza desde el ámbito global de la ONU en primer lugar, al ámbito regional del Mercosur en tercer lugar, pasando por la OEA, lo que lo aproxima en este orden de preferencias al PN y al PC. EI FA, por su parte, estructura sus preferencias de forma inversa. Va de la región más cercana a la más lejana, siguiendo el camino Mercosur, UNASUR, CELAC. Siendo la segunda la que concentra más menciones acumuladas y el Mercosur ocupa el segundo lugar solamente con una mención menos.

Para profundizar sobre estas diferentes miradas, es útil incorporar algunos elementos relativos al posicionamiento frente a procesos regionales. La evaluación del proceso de integración regional es un parte aguas entre partidos de derecha y partidos de izquierda en Brasil (ONUKI y OLIVEIRA 2010; y SILVA 2014). Lo mismo acontece en Uruguay. Aunque debe señalarse que la adhesión del FA al proceso mercosuriano tiene matices. Una forma de visibilizarlos es atender a tres aspectos 
específicos. El primero de ellos es la opinión sobre la deseabilidad de capacidades de producción de política pública a partir de poder legislar a nivel de bloque desde el Parlamento del Mercosur?

Tabela 7: Preferencias de los partidos sobre capacidades instituciones del Mercosur y la dinámica de los actores en este ámbito (Frecuencias).

\begin{tabular}{|c|c|c|c|c|c|c|c|c|c|}
\hline \multirow[b]{2}{*}{$\begin{array}{l}\text { Partid } \\
0\end{array}$} & \multicolumn{3}{|c|}{$\begin{array}{l}\text { Parlamento del Mercosur con } \\
\text { capacidad legislativa regional }\end{array}$} & \multicolumn{3}{|c|}{$\begin{array}{l}\text { Tribunal Permanente de } \\
\text { Revisión con } \\
\text { pronunciamientos vinculantes }\end{array}$} & \multicolumn{3}{|c|}{$\begin{array}{l}\text { No romper lógica nacional en } \\
\text { el Parlamento del Mercosur }\end{array}$} \\
\hline & $\begin{array}{c}\text { Acuerd } \\
0\end{array}$ & $\begin{array}{c}\text { Desacuerd } \\
0\end{array}$ & $\begin{array}{c}\mathrm{NS} / \mathrm{N} \\
\mathrm{C}\end{array}$ & $\begin{array}{c}\text { Acuerd } \\
0\end{array}$ & $\begin{array}{c}\text { Desacuerd } \\
0\end{array}$ & $\begin{array}{c}\mathrm{NS} / \mathrm{N} \\
\mathrm{C}\end{array}$ & $\begin{array}{c}\text { Acuerd } \\
0\end{array}$ & $\begin{array}{c}\text { Desacuerd } \\
0\end{array}$ & $\begin{array}{c}\mathrm{NS} / \mathrm{N} \\
\mathrm{C}\end{array}$ \\
\hline FA & 55 & 10 & 1 & 11 & 51 & 4 & 43 & 19 & 4 \\
\hline PN & 8 & 28 & 0 & 13 & 20 & 3 & 31 & 2 & 3 \\
\hline PC & 6 & 13 & 2 & 6 & 11 & 4 & 13 & 6 & 2 \\
\hline PI & 0 & 2 & 0 & 2 & 0 & 0 & 2 & 0 & 0 \\
\hline
\end{tabular}

Fonte: Elaboração dos autores a partir de pesquisa realizada com parlamentares uruguaios.

Como puede observarse en la tabla 7 , los parlamentarios del FA se muestran a favor de esta posibilidad, mientras que los parlamentarios de los restantes partidos se oponen. Desde el PC se señala el avance de la creación del Parlamento del Mercosur como un error, en palabras de uno de sus miembros: "El error es crear las instituciones políticas supranacionales antes que el mercado." Un senador del ala derecha del FA coincidió con esta apreciación, aunque señaló sus preferencias por profundizar la integración al señalar que:

Primero hay que fortalecer lo económico-comercial antes de avanzar con el Parlamento del Mercosur. Pero esto no quiere decir que estemos en contra. Creemos que es buena la supranacionalidad. [...] Hay que buscar un punto de equilibrio entre 'un país un voto' y la supranacionalidad.

Algunos parlamentarios del FA entrevistados señalaron a este espacio como un lugar de confluencia con otros partidos con ideas convergentes. En este sentido un senador afirmó que: "El Parlamento regional no está para defender el interés nacional, sino el interés común." Estas visiones presentan como telón de fondo una mirada particular sobre la soberanía. Un parlamentario frenteamplista reflexionaba de la siguiente manera sobre este aspecto:

Es importante construir gobernanza global. Eso no se puede hacer desde la antigua visión de la soberanía de los estados nación. Eso debe construirse desde procesos de compromisos compartidos a más grande escala que

\footnotetext{
${ }^{9}$ Hasta inicio de 2018 este órgano no tiene esta capacidad, tampoco tiene mecanismos claros de contralor sobre los órganos decisorios ni posee integración de parlamentarios uruguayos por método de elección directa por parte de la ciudadanía.
} 
generen soberanía. La gobernanza global asumida de forma compartida.

Aunque desde filas nacionalistas este proceso es visto como una amenaza para la soberanía nacional:

El Partido Nacional bloqueó avances de la política en la integración, por ejemplo en el Parlamento del Mercosur, con el tema de las mayorías. Ahí, algunos de nuestros compatriotas del MPP que tienen una mirada algo parecida a la nuestra, por nacionalistas, nos entendieron.

Algunas voces del FA señalan que la no profundización de la integración en clave productiva se debe a énfasis liberalizantes de parte de la izquierda, mientras que los frenos a la supranacionalidad provienen de algunas tendencias nacionalistas. En este sentido un diputado frenteamplista señaló: "La principal contradicción en el Frente Amplio, en materia de política exterior, es el resabio de carácter nacional chauvinista que hay en el tema de la integración."

El segundo punto que se consultó a los parlamentarios sobre el proceso de integración refirió al Tribunal Permanente de Revisión que es el órgano jurisdiccional del Mercosur. El mismo funciona desde 2004 y se encarga, entre otras funciones, de la solución de controversias entre los Estados Partes, teniendo capacidad de emitir laudos obligatorios pero no vinculantes, quedando el cumplimiento librado a la voluntad de las partes. Como puede observarse, la emisión de fallos vinculantes parece ser visto como una capacidad que afecta a la soberanía nacional. Todos los partidos, menos el PI, mostraron su desacuerdo con esto. Desde filas del PN, un senador señaló: "Lo único supranacional que se necesita es un tribunal de solución de controversias."

El último aspecto tiene que ver con la dinámica política dentro del Parlamento del Mercosur. Aquí se consultó sobre si preferían el funcionamiento por familias ideológicas o manteniendo una lógica de bloque nacional. En este caso todos los partidos mostraron una prevalencia de la lógica nacional como la preferida.

Dentro de FA existen distintas visiones a la hora de determinar la "familia ideológica regional", si bien existen consensos con relación al PT brasileño, e incluso con el Partido Socialista Chile o el Frente Guasú paraguayo, la incorporación de los peronistas y de otras izquierdas de perfil nacional - popular o neopopulistas, en el sentido dado por Jorge Lanzaro (2007), es menos consensuada dentro del partido de gobierno. 
Señalando estos matices, un parlamentario del ala derecha del FA señaló las diferencias que percibe entre los partidos en la región:

Con el PT tenemos un grado de hermanamiento. Con Argentina no nos pasa. [...] Yo no puedo sentirme cerca de la Campora, del Kirchnerismo. Eso es nacionalismo. [...] Yo no considero a los Kirchner de izquierda. Hay otros compañeros que sí, porque tienen una visión distinta, porque tienen otro grado de pragmatismo y lo comparan con Macri que es la derecha.

Desde el ala izquierda del FA, la afinidad con los procesos nacional populares se entienden en clave latinoamericanista, o de "Patria Grande". Un integrante de esta ala del FA señalaba: "Ellos no tienen una concepción latinoamericanista de la política exterior. Parten de cuestiones ideológicas. El liberalismo está pesando mucho en la izquierda [...]. Ahí te los junto con [Hermes] Binner $^{10}$. [...] Mientras que Mujica apoyó al kirchnerismo."

En temas de política exterior, los entrevistados, también señalaron matices con la izquierda chilena. Así lo manifestaba un senador frenteamplista:

Con el PT hicimos el Foro de San Pablo [...], esa fue la alianza privilegiada. En otros casos hay parientes lejanos, se puede dialogar en algunos campos, pero algunos tienen tal cúmulo de contradicciones e inconsistencia que no es posible. Con los chilenos a pesar de que la política exterior es distinta, ellos apostaron a la apertura total, estamos más cerca. No en política exterior por esta apuesta a la apertura total.

Como se desprende del análisis anterior, la participación en regímenes internacionales muestra las diferentes miradas sobre la concepción que se tiene de la soberanía. En la tabla 8 puede verse como la mayoría de los parlamentarios uruguayos están de acuerdo con la idea que plantea que los procesos que construyen supranacionalidad fortalecen a los Estados Partes al generar una nueva soberanía ampliada y compartida. Pero este posicionamiento varía si se observan las preferencias por partido. Mientras el FA muestra una postura favorable casi unánime, el PN muestra una mayoría en desacuerdo con esta idea. En el PC la mayoría está en contra, pero una proporción casi igual se manifestó de acuerdo con la idea de que los procesos supranacionales generan una soberanía ampliada y compartida. El PI divide sus opiniones en partes iguales a favor y en contra de esta idea.

\footnotetext{
${ }^{10}$ Líder del Partido Socialista Argentino, sector no peronista.
} 
Tabela 8: Percepciones de los parlamentarios uruguayos en torno a la soberanía, la supranacionalidad y la intergubernamentalidad en procesos de integración regional.

\begin{tabular}{|lcccccc|}
\hline & $\begin{array}{c}\text { Los procesos que construyen } \\
\text { supranacionalidad fortalecen a } \\
\text { los Estados Partes al generar una } \\
\text { nueva soberanía ampliada } \mathbf{y} \\
\text { compartida }\end{array}$ & $\begin{array}{l}\text { Las instituciones } \\
\text { intergubernamentales del } \\
\text { Mercosur son las que mejor } \\
\text { preservan la soberanía nacional }\end{array}$ \\
\hline Partido & Acuerdo & Desacuerdo & NS/NC & Acuerdo & Desacuerdo & NS/NC \\
\hline $\begin{array}{l}\text { Todos los } \\
\text { parlamentarios }\end{array}$ & 81 & 38 & 6 & 37 & 73 & 15 \\
\hline FA & 62 & 2 & 2 & 26 & 31 & 9 \\
\hline PN & 10 & 25 & 1 & 6 & 27 & 3 \\
\hline PC & 8 & 10 & 3 & 5 & 13 & 3 \\
\hline PI & 1 & 1 & 0 & 0 & 2 & 0 \\
\hline
\end{tabular}

Fonte: Elaboração dos autores a partir de pesquisa realizada com parlamentares uruguaios.

La segunda pregunta que se realizó a los parlamentarios sobre cómo la soberanía nacional es afectada por la participación en procesos de integración regional hacía referencia al Mercosur y consultaba si su estructura intergubernamental era la que mejor preservaba la soberanía nacional. Todos los partidos se posicionaron en desacuerdo frente a esta afirmación, y solamente el nivel de acuerdo es alto en el FA, aunque es minoritario. En el FA el 39,4\% de los consultados estuvo de acuerdo con que las instituciones intergubernamentales del Mercosur son las que mejor preservan la soberanía nacional. Un $47 \%$ de los frenteamplistas estuvo en contra de la afirmación y el $13,6 \%$ no respondió.

En el caso uruguayo la evidencia empírica muestra un "discreto encantamiento" de la izquierda uruguaya con la integración regional. Las posturas intrapartidarias no son homogéneas, incluso llegando a mostrar divergencias importantes, y parecen imperar lógicas que reivindican la soberanía nacional y el interés nacional por sobre las lógicas ideológicas. Esto es, compartir soberanía en esquemas supranacionales es deseable para la izquierda uruguaya, pero a la hora de pensar casos concretos la convicción comienza a decrecer. Incluso, en ámbitos como el Parlamento del Mercosur, los parlamentarios manifiestan estar más proclives a la actuación por bloques país que por familias ideológicas.

Tabela 9: Actor que debe intervenir en conflicto armado en la región. 


\begin{tabular}{|cc|}
\hline & Porcentaje \\
\hline ONU & 32,0 \\
\hline OEA & 10,4 \\
\hline EEUU & 0,8 \\
\hline UNASUR & 36,0 \\
\hline Mercosur & 12,8 \\
\hline Un grupo de países de la región & 2,4 \\
\hline Un grupo de países de fuera de la región & 0,8 \\
\hline Nadie & 1,6 \\
\hline Total & 96,8 \\
\hline NS/NC & 3,2 \\
\hline Total & 100,0 \\
\hline
\end{tabular}

Fonte: Elaboração dos autores a partir de pesquisa realizada com parlamentares uruguaios.

Estos posicionamientos divergentes también aparecen frente cuál es la institución que debería intervenir en un hipotético caso de conflicto armado en la región. Esto muestra claras diferencias entre izquierda y derecha en el sistema político uruguayo. A pesar que, al tomar a los parlamentarios como un único grupo, la UNASUR es la institución que nuclea más preferencias (tabla 9), pueden verse las divergencias al segmentar las respuestas por partidos.

Tabela 10: Actor que debe intervenir en conflicto armado en la región.

\begin{tabular}{|c|c|c|}
\hline & & Porcentaje \\
\hline \multirow[t]{7}{*}{ FA } & ONU & 10,6 \\
\hline & OEA & 3,0 \\
\hline & UNASUR & 62,1 \\
\hline & Mercosur & 18,2 \\
\hline & Un grupo de países de la región & 4,5 \\
\hline & Un grupo de países de fuera de la región & 1,5 \\
\hline & Total & 100,0 \\
\hline \multirow[t]{8}{*}{ PN } & ONU & 50,0 \\
\hline & OEA & 19,4 \\
\hline & UNASUR & 8,3 \\
\hline & Mercosur & 11,1 \\
\hline & Nadie & 5,6 \\
\hline & Total & 94,4 \\
\hline & $\mathrm{NS} / \mathrm{NC}$ & 5,6 \\
\hline & Total & 100,0 \\
\hline \multirow[t]{7}{*}{ PC } & ONU & 66,7 \\
\hline & OEA & 19,0 \\
\hline & EEUU & 4,8 \\
\hline & UNASUR & 4,8 \\
\hline & Total & 95,2 \\
\hline & $\mathrm{NS} / \mathrm{NC}$ & 4,8 \\
\hline & Total & 100,0 \\
\hline \multirow[t]{3}{*}{$\mathbf{P I}$} & ONU & 50,0 \\
\hline & $\mathrm{NS} / \mathrm{NC}$ & 50,0 \\
\hline & Total & 100,0 \\
\hline
\end{tabular}


Fonte: Elaboração dos autores a partir de pesquisa realizada com parlamentares uruguaios.

Al ver las preferencias por partidos (tabla 10) puede observarse que mientras el Frente Amplio prioriza la acción de la institucionalidad regional, en primer lugar la UNASUR con 62,1\% de las preferencias y el Mercosur con 18,2\% de las preferencias, el resto de los partidos prefiere la acción de las Naciones Unidas. Por otra parte, tanto el Partido Nacional como el Partido Colorado muestran una segunda preferencia que en ambos casos señala a la OEA. Debe decirse que desde la izquierda uruguaya existen algunas críticas a la OEA, particularmente en lo que atañe al peso que Estados Unidos de América tiene en este ámbito panamericano.

\subsection{Los ciudadanos uruguayos frente a los regímenes internacionales}

Como se señaló anteriormente, el sistema de partidos uruguayo posee un alto nivel de institucionalización y de correspondencia ideológica. Esto no solo impacta en el posicionamiento de los representantes parlamentarios, alineado ideológicamente al posicionamiento de los partidos que representan, sino que también se da entre votantes y los partidos que dicen preferir, así como también cuando se les interroga sobre su intención de voto en una próxima elección.

Al momento de relevar los datos para Uruguay, la distribución de preferencias partidarias se presentó de la siguiente manera:

Tabela 11: Partido que prefiere.

\begin{tabular}{|cc|}
\hline & Porcentaje \\
\hline Muy Frentista & 14,3 \\
\hline Algo Frentista & 21,7 \\
\hline Muy Colorado & 3,9 \\
\hline Algo Colorado & 4,4 \\
\hline Muy Blanco & 6,0 \\
\hline Algo Blanco & 7,6 \\
\hline Ninguno & 37,0 \\
\hline Otros & 1,1 \\
\hline Total & 96,0 \\
\hline No contesta & 4,0 \\
\hline Total & 100,0 \\
\hline
\end{tabular}

Fonte: Elaboração dos autores a partir da pesquisa mundial de valores 
En términos de intención de voto al momento de relevar los datos de la EMV en 2006, la distribución de la intención de voto era la siguiente:

Tabela 12: Qué partido votaría

\begin{tabular}{|cc|}
\hline & Porcentaje \\
\hline Partido Colorado & 7,5 \\
\hline Partido Nacional & 14,2 \\
\hline Frente Amplio & 38,9 \\
\hline Partido Independiente & 1,8 \\
\hline Ninguno & 14,7 \\
\hline Otros & 1,6 \\
\hline Total & 78,8 \\
\hline No contesta & 21,2 \\
\hline Total & 100,0 \\
\hline
\end{tabular}

Fonte: Elaboração dos autores a partir da pesquisa Mundial de Valores

El orden de preferencia partidario mantiene el orden de intención de voto, aunque en el caso del Frente Amplio es mayor la distancia entre quienes se sienten frenteamplistas y aquellos que dicen que votarían por este partido en una próxima elección (37,5\% vs $49,4 \%$ ). Los partidos nacional y colorado presentan menores dispersiones entre ambas variables $(14,2 \%$ vs $18,1 \%$ para el Partido Nacional, y $8,7 \%$ vs $9,5 \%)$.

En síntesis, y apelando nuevamente al posicionamiento ideológico de los partidos descrito anteriormente, poco más de un tercio de la población se ubica a la izquierda en el eje ideológico, mientras que poco más de una quinta parte lo hace a partir de la centroderecha y la derecha.

Si bien los temas internacionales y de política exterior pueden resultar ajenos a los ciudadanos debido a falta de conocimiento o interés (LIPSET, 1966; MORA Y ARAUJO, 2005), Uruguay es un país con una inserción internacional variada tanto a nivel comercial como político, y por lo tanto los asuntos de esa materia son tema de discusión y generan impacto y cambio en la estructura de la opinión pública cuando se presenta algún conflicto.

Entre las áreas de inserción de Uruguay en el campo de la política exterior, una de las más antiguas y de mayor percepción entre la ciudadanía es la de la 
cooperación en el ámbito militar, integrando diferentes misiones de paz de las Naciones Unidas. Asuntos vinculados al mantenimiento de la paz en zonas de conflicto aparecen con frecuencia en la agenda pública, y han sido incluso materia de discusión a nivel legislativo.

De los distintos escenarios que se le plantean a los respondentes de la EMV, existe uno que indaga sobre la responsabilidad en el mantenimiento de la paz a nivel internacional. Las opciones que se ofrece a quienes responden son: gobiernos nacionales; organismos regionales; o Naciones Unidas.

\section{Tabela 13: Quién debiera decidir: mantenimiento de la paz internacional}

\begin{tabular}{|cc|}
\hline & Porcentaje \\
\hline Gobiernos nacionales & 15,8 \\
\hline Organización regional & 11,6 \\
\hline Naciones Unidas & 67,3 \\
\hline Total & 94,7 \\
\hline No contesta & 5,3 \\
\hline Total & 100,0 \\
\hline
\end{tabular}

Fonte: Elaboração dos autores a partir da pesquisa Mundial de Valores

Posiblemente, por tratarse de un asunto planteado a nivel internacional, la mayoría de las respuestas (71\%) adjudiquen a las Naciones Unidas la responsabilidad en el mantenimiento de la paz. Aunque poco significativa, existe además una mayor asignación de responsabilidad a gobiernos nacionales que a organismos regionales.

En alguna medida, el nivel de estas respuestas puede estar definido por el sentimiento de pertenencia a cada una de estas unidades administrativas, que podría señalar cuán global o local es la visión de la opinión pública respecto de los distintos asuntos tratados en la EMV. Un grupo de preguntas de esta serie (210 a 214) solicita al respondente que se defina en función de su relación con el mundo, a partir de grados de acuerdo con la frase "me considero ...", manejando las opciones "ciudadano del mundo"; "parte de mi comunidad local"; "parte de la nación ..."; "parte de ..." (el organismo regional que corresponda al país en que se aplica la EMV); "me veo como un individuo autónomo".

Tomando tres de los niveles de identificación solicitados -mundo, región y nación- los uruguayos se ubicaron de la siguiente manera: 
Tabela 14: Me considero (\%)

\begin{tabular}{|ccrr|}
\hline & $\begin{array}{c}\text { ciudadano } \\
\text { del mundo }\end{array}$ & $\begin{array}{c}\text { ciudadano } \\
\text { del Mercosur }\end{array}$ & $\begin{array}{c}\text { ciudadano de } \\
\text { Uruguay }\end{array}$ \\
\hline Muy de acuerdo & 18,5 & 12,1 & 36,7 \\
\hline De acuerdo & 59,5 & 43,6 & 55,8 \\
\hline En desacuerdo & 18,7 & 32,9 & 6,0 \\
\hline $\begin{array}{c}\text { Muy en } \\
\text { desacuerdo }\end{array}$ & 2,5 & 8,5 & 1,0 \\
\hline Total & 99,2 & 97,1 & 99,5 \\
\hline No contesta &, 8 & 2,9 &, 5 \\
\hline Total & 100,0 & 100,0 & 100,0 \\
\hline
\end{tabular}

Fonte: Fonte: Elaboração dos autores a partir da pesquisa Mundial de Valores

Como es razonable esperar, los uruguayos mayoritariamente muestran valores superiores de acuerdo respecto de su pertenencia al país (tabla 14), con un 93\% de respuestas en las categorías "muy de acuerdo" y "de acuerdo". Sin embargo, si planteamos una visión menos local, se registra un mayor nivel de acuerdo con la identificación con la comunidad mundial que con la regional. Casi un $60 \%$ de los respondentes se identificó más favorablemente con la idea de pertenencia al Mercosur, frente a un $79 \%$ en el que el acuerdo con la idea de pertenencia a nivel internacional fue señalada positivamente. El privilegio de una identificación más global frente a una más regional en materia de pertenencia, favorece el señalamiento de las Naciones Unidas como un actor más relevante para el mantenimiento de la paz internacional que el Mercosur u otro entramado institucional de carácter regional. Por otra parte, la importante presencia del ejército uruguayo como integrante de diversas misiones de paz de la ONU y su difusión a través de los medios de comunicación probablemente impactan también en esa mayor atribución en el mantenimiento de la paz.

Así como la pertenencia partidaria configura las alineaciones de los dirigentes políticos en materia de relaciones internacionales, es esperable que las preferencias de los ciudadanos puedan tener algún impacto en sus niveles de identificación entre una escala nacional y una más global. 
Tabela 17: Quién debiera decidir el mantenimiento de la paz internacional, por preferencia partidaria.

\begin{tabular}{|llllllllll|}
\hline & \multicolumn{8}{c|}{ Partido que prefiere } \\
\cline { 2 - 10 } & Ninguno & Otros & $\begin{array}{l}\text { Muy } \\
\text { Frentista }\end{array}$ & $\begin{array}{l}\text { Algo } \\
\text { Frentista }\end{array}$ & $\begin{array}{l}\text { Muy } \\
\text { Colorado }\end{array}$ & $\begin{array}{l}\text { Algo } \\
\text { Colorado }\end{array}$ & $\begin{array}{l}\text { Muy } \\
\text { Blanco }\end{array}$ & $\begin{array}{l}\text { Algo } \\
\text { Blanco }\end{array}$ & Total \\
\hline $\begin{array}{l}\text { Gobierno } \\
\text { nacional }\end{array}$ & 16,0 & 18,2 & 12,9 & 18,4 & 10,8 & 17,1 & 25,9 & 16,4 & 16,6 \\
\hline $\begin{array}{l}\text { Organización } \\
\text { regional }\end{array}$ & 13,1 & 27,3 & 12,1 & 10,7 & 13,5 & 12,2 & 3,4 & 12,3 & 11,9 \\
\hline $\begin{array}{l}\text { Naciones } \\
\text { Unidas }\end{array}$ & 70,9 & 54,5 & 75,0 & 70,9 & 75,7 & 70,7 & 70,7 & 71,2 & 71,5 \\
\hline Total & 100,0 & 100,0 & 100,0 & 100,0 & 100,0 & 100,0 & 100,0 & 100,0 & 100,0 \\
\hline
\end{tabular}

Fonte: Elaboração dos autores a partir da pesquisa Mundial de Valores

La tabla 17 nos muestra la distribución de las opiniones de los ciudadanos respecto de cuál es el actor que debiera encargarse del mantenimiento de la paz a nivel internacional, distribuido por las preferencias partidarias manifestadas en dos grados de intensidad. Independientemente de lo expresado en torno a la identificación partidaria, los respondentes de la EMV mayoritariamente asignan a las Naciones Unidas la principal posición en el mantenimiento de la paz en más de dos tercios, salvo para quienes se identifican con la opción "otros". Tampoco las preferencias partidarias parecen incidir en la importancia otorgada a los gobiernos nacionales y a los organismos regionales, a excepción de aquellos que se consideran "muy blancos" (Partido Nacional), que privilegian el rol de los gobiernos nacionales por sobre los organismos regionales para el mantenimiento de la paz a nivel internacional.

\section{A modo de síntesis y para concluir}

Una primera constatación empírica que debe realizarse sobre el caso uruguayo, a partir de los datos presentados, es que las preferencias de los actores políticos sobre los diferentes OIG y regímenes internacionales a los que adhiere el Estado muestran divergencias. Por su parte, estas divergencias parecen relacionarse con el posicionamiento ideológico de los partidos en el eje unidimensional izquierda-derecha. Mientras que la direccionalidad de la relación parece indicar que cuanto más a la izquierda se posicionan los actores, mayor es la adhesión a los procesos de integración regional y su institucionalidad, siendo este 
espacio regional el latinoamericano, sudamericano o mercosuriano.

Esta última aclaración responde a que ningún actor rechaza participar de espacios institucionales donde los asuntos políticos, incluidos los de seguridad internacional y defensa, tienen un lugar importante. Aquí lo que varía es el espacio institucional regional privilegiado. Mientras los actores que se posicionan más a la izquierda apuestan por espacios como la UNASUR, probablemente también influidos por el liderazgo del Brasil gobernado por el Partido de los Trabajadores (PT) que marcaba el contexto en el momento de recoger los datos. Mientras que los actores ubicados en posiciones que van del centro a la derecha del espectro ideológico visualizan a la OEA como el espacio institucional regional. Este último convergiendo con un espacio institucional con fuerte presencia del EEUU. Para estos actores la UNASUR y la CELAC no aparecen como espacios institucionales atractivos, siendo criticados por ellos, a partir de argumentos que señalan "ideologización".

Estos actores, ubicados desde el centro a la derecha del continuo ideológico, encuentran en el Mercosur una plataforma, casi exclusivamente, para la inserción económico-comercial con el mundo. Los avances en arreglos institucionales en otras dimensiones que no es esta son vistas con desconfianza. El espacio de los asuntos políticos para estos actores es la OEA. Mientras que los ubicados a la izquierda ponen dimensiones políticas, incluidas las de seguridad internacional y defensa, en el marco de UNASUR.

Sin embargo, los actores de izquierda que, en términos relativos con los de centro derecha, se manifiestan más favorables de integrarse a espacios institucionales regionales, transfiriendo capacidad decisoria a los mismos, puestos frente a situaciones concretas parecen retraerse sobre posiciones más soberanistas que tienen al Estado Nacional como el actor central. El análisis de estas tensiones y la búsqueda de sus mecanismos causales demandan una investigación que excede los horizontes de este trabajo, pero estas cuestiones que quedan abiertas pueden constituirse en elementos iniciales para la formulación de una agenda futura de investigación.

Por su parte, el PC y el PN no tienen posiciones del todo homogéneas entre sí. El PC muestra un mayor componente panamericanista e internacionalista, 
coherente con su tradición política en esta arena, sucediendo lo mismo con el nacionalismo constitutivo de la tradición del PN, que incluso recoge elementos regionalistas de tipo hispanocriollo y resistente frente a lo europeo y estadounidense. Incluir variables relativas a las tradiciones políticas y, particularmente, sobre como aparece el relacionamiento con los países más poderosos en este marco, constituye otro posible camino en la indagatoria, pero ya por la senda de la teoría de la autonomía que tienen a Helio Jaguaribe y Juan Carlos Puig como precursores ${ }^{11}$.

Por último vale la pena referirse a las diferencias que parecen existir entre las preferencias de los parlamentarios y los ciudadanos. Estos últimos parecen no registrar el debate divergente sobre los regímenes internacionales que si se visualiza entre las preferencias de los parlamentarios. La política exterior y la pertenencia a regímenes internacionales, como parte de la agenda de esta arena de política pública, pueden ser asuntos muy alejados de la cotidianidad ciudadana y estos ser parte de los factores que expliquen esta diferencia de preferencias con relación a los actores políticos.

Los ciudadanos parecen estar menos imbuidos en el debate sobre la pertenencia a los regímenes internacionales de carácter regional. A la vez que parecen tener una mayor propensión a preferir los espacios institucionales internacionales, particularmente la ONU. Esto puede verse al analizarse las opiniones de los ciudadanos sobre el mantenimiento de la paz y la seguridad internacional. Eso también podría responder a la alta visibilidad de la participación uruguaya en las Operaciones de Mantenimiento de la Paz de la ONU. Un asunto que, sin embargo, ha registrado un importante debate entre actores políticos y de la sociedad civil en varias oportunidades, tanto en el ámbito parlamentario como a través de los medios de comunicación. Un análisis más detallado y en profundidad podría develar alguna posible explicación para el alto consenso registrado por parte de los ciudadanos en relación a la ONU y su rol en el tema de seguridad internacional tratado en este texto.

En síntesis, los asuntos visibilizados por el análisis empírico no permiten extraer conclusiones contundentes sobre las explicaciones causales de los

\footnotetext{
${ }^{11}$ Un análisis sobre la construcción teórica del concepto de autonomía puede encontrarse en Briceño y Simonoff, 2017.
} 
fenómenos observados, pero si contribuyen a la acción de pensar en algunas líneas orientadoras para procesos de indagación futura, ya que es relevante mejorar nuestras preguntas y agregar nuevas para optimizar el impulso investigativo sobre estos asuntos. La estrategia comparada podría resultar de gran utilidad, ya que la tensión por la apuesta a la región o la apertura al mundo parece estar presente en varios países de América del Sur. El correlato de estas apuestas con las preferencias y posicionamientos frente a diferentes OIG y regímenes internacionales es un posible camino para explorar el potencial de los hallazgos del caso uruguayo a una escala mayor, inicialmente subregional. Por el momento, las reflexiones que permite el caso analizado solamente nos ayudan a mejorar nuestras preguntas e hipótesis y pensar una agenda futura de investigación.

\section{Referencias bibliográficas}

BRICEÑO, José y Alejandro SIMONOFF. La Escuela de la Autonomía, América Latina y la teoría de las relaciones internacionales. Estudios Internacionales, v.49, n.186, p. 39-89, 2017.

BUQUET, Daniel y Rafael PIÑEIRO. La consolidación de un nuevo sistema de partidos en Uruguay. Debates, v.8, n.1, p. 127-148, 2014.

CAETANO, Gerardo, Camilo LÓPEZ BURIAN y Carlos LUJÁN. La política exterior uruguaya entre Vázquez y Vázquez (2010-2015). En: José Busquets y Nicolás Bentancur (coords.). El decenio progresista. Las políticas públicas de Vázquez a Mujica. Fin de siglo: Montevideo, 2016. p. 279-300.

CAETANO, Gerardo, José RILLA y Romeo PÉREZ. La partidocracia uruguaya. Historia y teoría de la centralidad de los partidos políticos. Cuadernos del CLAEH, v.44, n.1, p. 36-61, 1987.

GONZÁLEZ, Luis Eduardo. Estructuras políticas y democracia en Uruguay. Montevideo: FCU-ICP, 1993.

GRASA, Rafael. Neoliberalismo e institucionalismo. La reconstrucción del liberalismo como teoría sistémica internacional. En Celestino del Arenal y José Antonio Sanahuja (ccords.). Teoría de las relaciones internacionales. Tecnos: Madrid, 2015. P.97-125.

HAAS, Ernst. International integrations: the European and the universal process. International Organization, v.15, n.3. p. 366-392, 1961.

HARTLEY, Thomas y Bruce RUSSETT. Public Opinion and the Common Defense: 
Who Governs Military Spending in the United States? American Political Science Review, v.86, n.1, p.905-915, 1992.

HOLSTI, Ole R. Public opinion and foreign policy: Challenges to the AlmondLippmann consensus. International Studies Quarterly, v.36, n.4, p.439-466, 1992.

KEOHANE, Robert y Joseph NYE. Poder e Interdependencia. La política internacional en transición. Buenos Aires: GEL, 1988.

KRASNER, Steven. Structural causes and regime consequences: regimes as intervening variables. International Organization, v.36, n.2. p. 185-205, 1982.

LAMPREIA, Luiz Felipe. A política externa do governo FHC: continuidade e renovação. Revista brasileira de política internacional, v.41, n. 2, p. 5-17, 1998.

LIPSET, Seymour Martin. The president, the polls, and Vietnam. Transactions, v.3, n.1. p. 20-22, 1966.

LÓPEZ BURIAN, Camilo. UNASUR en la política exterior uruguaya. El posicionamiento de los partidos políticos durante el gobierno de José Mujica (2010 2014). Revista Perspectivas de Políticas Públicas, v.7, n.1, p. 185-225, 2014.

LOPEZ BURIAN, Camilo. Partidos políticos y política exterior en Uruguay (1985 2015). La importancia de las instituciones, las ideas y los intereses de los actores. Tesis de Doctorado en Ciencia Política, Universidad de la República (Uruguay), 2015.

LUJÁN, Carlos. La política internacional del primer gobierno de izquierda en el Uruguay: continuidades y cambios. En María Ester Mancebo y Pedro Narbondo (coords.). Reforma del Estado y políticas públicas de la Administración Vázquez: acumulaciones, conflictos y desafíos. Montevideo: Fin de Siglo-CLACSO-ICP. p. 352 $-370.2010$

MALLMANN, Maria Izabel. Análise institucionalista da integração sul-americana. Civitas, v.10, n.1. p. 11-22, 2010.

MALLOY, Jonathan. High Discipline, Low Cohesion? The Uncertain Patterns of Canadian Parliamentary Party Groups. Journal of Legislative Studies, v.9, n.4, p. 116-129, 2003.

MARKS, Gary, Carol WILSON y Leonard RAY. National Political Parties and European Integration. American Journal of Political Science, v.46, n.3, p. 585-594, 2002

MILNER, Helen y Benjamin JUDKINS. Partisanship, Trade Policy, and Globalization: Is There a Left-Right Divide on Trade Policy? International Studies Quarterly, v.48, n.1. p. 95-119, 2004.

MINGST, Karen. Fundamentos de las relaciones internacionales. México DF: CIDE. 
MORA Y ARAUJO, Manuel. El poder de la conversación: elementos para una teoría de la opinión pública. Buenos Aires: La Crujía, 2005.

MORENO, Alejandro. Nuestros valores: los mexicanos en México y en Estados Unidos al inicio del Siglo XXI. México DF: Banamex.

PAGE, Benjamin y Marshall BOUTON. The foreign policy disconnect. What Americans want from our leaders but don't get. Chicago: University of Chicago Press, 2006.

PATERSON, Thomas. Presidential Foreign Policy, Public Opinion, and Congress: The Truman Years. Diplomatic History, v.3, n.1. p.1-18, 1979.

RISSE-KAPPEN, Thomas. Public opinion, domestic structure, and foreign policy in liberal democracies. World Politics, v.43, n.4, p.479-512, 1991.

ROSENAU, James. Democracy and Foreign Policy. New York y Londres: Free Press and Collier-Macmillan, 1967.

RUGGIE, John. International responses to technology: Concepts and trends. International Organization, v.29, n.3, p. 557-583, 1975.

SARAIVA, Miriam Gomes y TEDESCO, Laura. "Argentina y Brasil. Políticas exteriores comparadas tras la Guerra Fría". En: Vicente Palermo (comp.). Política Brasileña Contemporánea. De Collor a Lula en años de transformación. Buenos Aires: ITDT - Siglo XXI, 2004. p.475-512.

SOBEL, Richard. The Impact of Public Opinion of U.S. Foreign Policy Since Vietnam. New York: Oxford University Press, 2001.

THÉRIEN, Jean-Philippe y Alan NOEL. Political Parties and Foreign Aid. The American Political Science Review, v.94, n.1. p. 151-162, 2000.

WITTKOPF, Eugene R. Faces of Internationalism: Public Opinion and American Foreign Policy. Durham: Duke University Press, 1990.

ZUASNABAR, Ignacio, Claudia RAFANIELLO, Matías DODEL y Federico RODRİGUEZ. Los valores en Uruguay: tendencias y cambios. Montevideo: Universidad Católica del Uruguay/Fundación Konrad Adenauer, 2010.

Recebido em 05/03/2018.

Aprovado em 10/05/2018 